\title{
219-S Corrosion Study
}

Prepared by James R. Divine

Prepared for: Tank Farm Contractor, WRPS

Richland, WA 99352

U.S. Department of Energy Contract DE-AC27-08RV14800

$\begin{array}{llll}\text { EDT/ECN: } & \text { DRF } & \text { UC: N/A } & \\ \text { Cost Center: } & \text { N/A } & \text { Charge Code: } & \text { N/A } \\ \text { B\&R Code: } & \text { N/A } & \text { Total Pages: } & 10\end{array}$

Key Words: 219-S, 222-S, Laboratory, Corrosion, Drain, Weld, Pipe, Piping.

Abstract: This study assesses improvements to operational activities that may be implemented to extend the tank and piping system life expectancy.

TRADEMARK DISCLAIMER. Reference herein to any specific commercial product, process, or service by trade name, trademark, manufacturer, or otherwise, does not necessarily constitute or imply its endorsement, recommendation, or favoring by the United States Government or any agency thereof or its contractors or subcontractors.
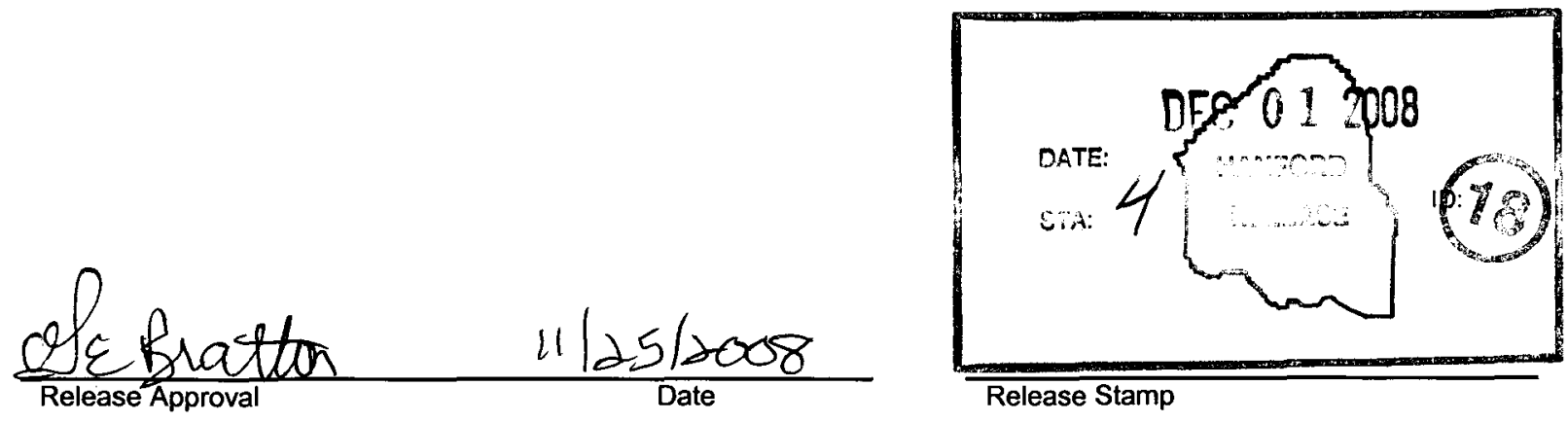

\section{Approved For Public Release}


RPP-39617, Rev. 0

219S-CML-8

PAGE 1 of 8

\section{9-S CORROSION REVIEW}

Prepared by:

James R Divine, $\mathrm{PhD} P \mathrm{PE}$

Corrosion Specialist \# 867

ChemMet, Ltd., PC

POB 4068

West Richland, Washington 99353

for

CH2M Hill Hanford Group

PO Box 1500

Richland, WA 99352

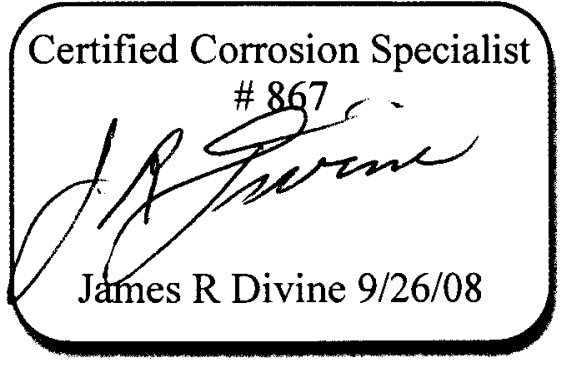

September 26, 2008 


\section{TABLE OF CONTENTS}

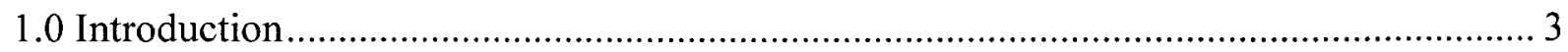

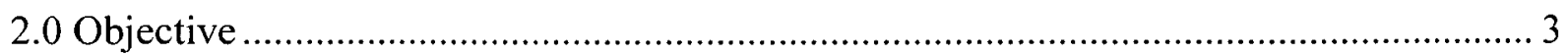

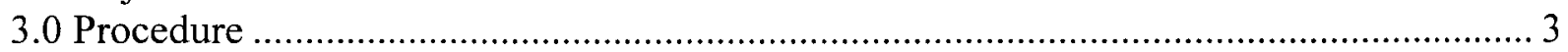



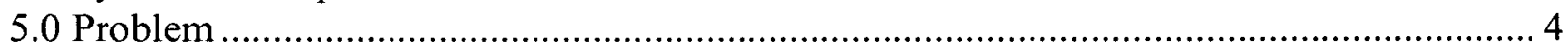

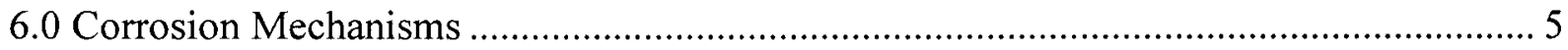

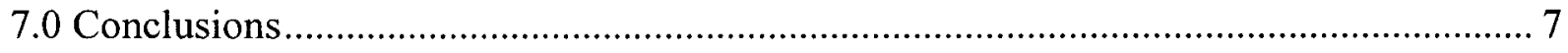

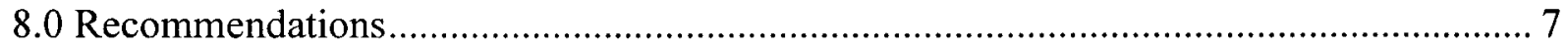

\section{TABLE OF FIGURES}

Figure 1: Surface Pits and Through-wall Pits at the Weld................................................. 5

Figure 2: Surface Deposits Around Pit ...................................................................... 6

Figure 3: Chloride vs pH limits for Stainless Alloys.................................................. 6

Figure 4: Leak Numbers for Untreated Lines ............................................................ 7 
RPP-39617, Rev. 0

219S-CML-8

PAGE 3 of 8

\section{9-S Corrosion Review}

\subsection{Introduction}

A minor leak was detected in a drain line for Hood 2B located in the 222-S Laboratory. The line transfers radioactive waste, spent analytical standards, and chemicals used in various analytical procedures. Details are in the report provided by David Comstock, $2 B N D E$ June 2008, work package LAB-WO-07-2012. Including the noted leak, the 222-S Laboratory has experienced two drain line leaks in approximately the last two years of operation.

As a consequence, CH2M HILL Hanford Group, Inc. (CH2M HILL) requested the support of ChemMet, Ltd., PC (ChemMet) at the Hanford Site 222-S Laboratory. The corrosion expertise from ChemMet was required prior to preparation of a compatibility assessment for the 222-S Laboratory waste transfer system to assure the expected life of the piping system is extended as much as practicable. The system includes piping within the 222-S Laboratory and the 219-S Waste Storage and Transfer Facility and Operations Process.

\subsection{Objective}

The ChemMet support was required for an assessment by 222-S staff to analyze what improvements to operational activities may be implemented to extend the tank/piping system life. This assessment will include a summary of the various material types, age, and locations throughout the facility. The assessment will also include a discussion of materials that are safe for drain line disposal on a regular basis, materials that are safe for disposal on a case-by-case basis including specific additional requirements such as flushing, neutralization to a specific $\mathrm{pH}$, and materials prohibited from disposal. The assessment shall include adequate information for 222-S Laboratory personnel to make informed decisions in the future disposal of specific material types by discussing types of compatibility of system materials and potential wastes. The assessment is expected to contain some listing of acceptable waste materials but is not anticipated to be a complete or comprehensive list. Finally the assessment will encompass a brief discussion of acceptable limits for pipe degradation and references to applicable codes and standards.

\subsection{Procedure}

A committee was formed consisting of 222-S laboratory personnel to evaluate the Laboratory Operating Procedures, that is the procedure for slurp and pour and its effects upon the drain lines and the 219-S receiving tanks. The committee requested ChemMet provide the services of James R. Divine, PhD., PE, FNACE as the corrosion expert. Dr. Divine's role was to evaluate data associated with both the slurp and pour as well as the analytical data associated with the 291-S transfer to tank farms. ChemMet also participated in meetings to discuss the assessment, comments, and other input.

ChemMet reviewed input prepared by 222-S Laboratory staff and included constructive comments for incorporation into the document. Input to the document used ChemMet's corrosion expertise to provide specific details on acceptable mixtures, waste $\mathrm{pH}$, etc. 
Multiple reviews of the assessment were required as comments were incorporated.

\subsection{System Description}

The 222-S Laboratory was constructed in 1950-51 to provide analytical chemistry services for the Hanford Site projects, operations, and environmental cleanup activities. Currently the 222-S Laboratory has a long-term mission to support the Hanford Site environmental cleanup and restoration activities including support to the Waste Treatment Plant. Laboratory personnel complete organic, inorganic, and radioactive analyses of liquid and solid samples. The laboratory has been progressively expanded as warranted by mission need. Many portions of the laboratory and corresponding 219-S facility have been upgraded over the last 50 years to include secondary containment for waste transfer lines and the 219-S facility. Though upgrades have been made throughout the facility, some piping is at least 20 years old and the two tanks in the 219-S facility are original. Due to the age of 222-S liquid waste handling systems, the piping and tanks are prone to leaks and degradation. Acids and bases are transferred utilizing the liquid waste transfer system on a daily basis. The tanks and lines are reportedly constructed of ASTM A312 types 304L and 347 stainless steel.

\subsection{Problem}

Many of the more than 80 procedures performed at 222-S with Waste Stream Fact Sheets were reviewed by ChemMet. Examples of the chemicals involved are:

- mix of $10 \% \mathrm{HCl}, 40 \% \mathrm{HNO}_{3}, 40 \% \mathrm{H}_{2} \mathrm{SO}_{4}$

- $13 \% \mathrm{HNO}_{3}, 5 \% \mathrm{HF}$

- $40 \% \mathrm{NaOH}$

- mix of $30 \%$ chlorides, $30 \% \mathrm{HNO}_{3}, 30 \% \mathrm{HF}$

Most of the spent chemicals and the associated matrix are deleterious to the materials of construction, for example $304 \mathrm{~L}$, schedule 40 pipe. While some, like $\mathrm{HNO}_{3}$ at most concentrations are innocuous, combinations can be synergistic:

- $10 \% \mathrm{HNO}_{3}$ about $0.1 \mathrm{mpy}(0.0001 \mathrm{inch} / \mathrm{y})$ - negligible concern

- $3 \% \mathrm{HF}$ about $100 \mathrm{mpy}(0.1 \mathrm{inch} / \mathrm{y})$ - serious concern

- $10 \% \mathrm{HNO}_{3}+3 \% \mathrm{HF}$ over $4,000 \mathrm{mpy}(4 \mathrm{inch} / \mathrm{y})$ - extremely serious concern

Similarly $\mathrm{H}_{2} \mathrm{SO}_{4}$ and particularly $\mathrm{HCl}$ are very aggressive at most concentrations.

While the waste just prior to final transfer to the tank farms has been found to be acceptable, no information of the normal conditions is available. 219-S conditions prior to transfer were:

\section{Year 2004}

- $\mathrm{pH} 12.8$

- Chloride $1100 \mathrm{mg} / \mathrm{L}$ (ppm)

Year 2005

- $\mathrm{pH} 12.3$

- $\quad$ Chloride $470 \mathrm{mg} / \mathrm{L}$ (ppm) 


\section{Year 2006}

- $\mathrm{pH} 12$

- $\quad$ Chloride $860 \mathrm{mg} / \mathrm{L}(\mathrm{ppm})$

Year 2007

- $\mathrm{pH} 13.1$

- $\quad$ Chloride $540 \mathrm{mg} / \mathrm{L}(\mathrm{ppm})$

\subsection{Corrosion Mechanisms}

The 300 series austenitic stainless steels such as types 304L and 347 are noted for their corrosion resistance. As pointed out above, these materials are virtually immune to corrosion by nitric acid under the conditions experienced at 222-S Laboratory. When mixed with hydrofluoric acid, the uniform corrosion rate can increase greatly. Hydrochloric acid will cause rapid corrosion of the steels by itself and in conjunction with nitric acid.

In addition, 304L, though relatively immune to stress corrosion cracking, can crack at sufficiently high temperature or at high chloride concentrations. Type 347 is more immune to cracking.

However, both alloys are extremely susceptible to chloride induced pitting. At the West Valley Nuclear site, a mere 200 ppm chloride concentration, combined with poor welds, produced pitting as shown in Figures 1 and 2.



Figure 1: Surface Pits and Through-wall Pits at the Weld 


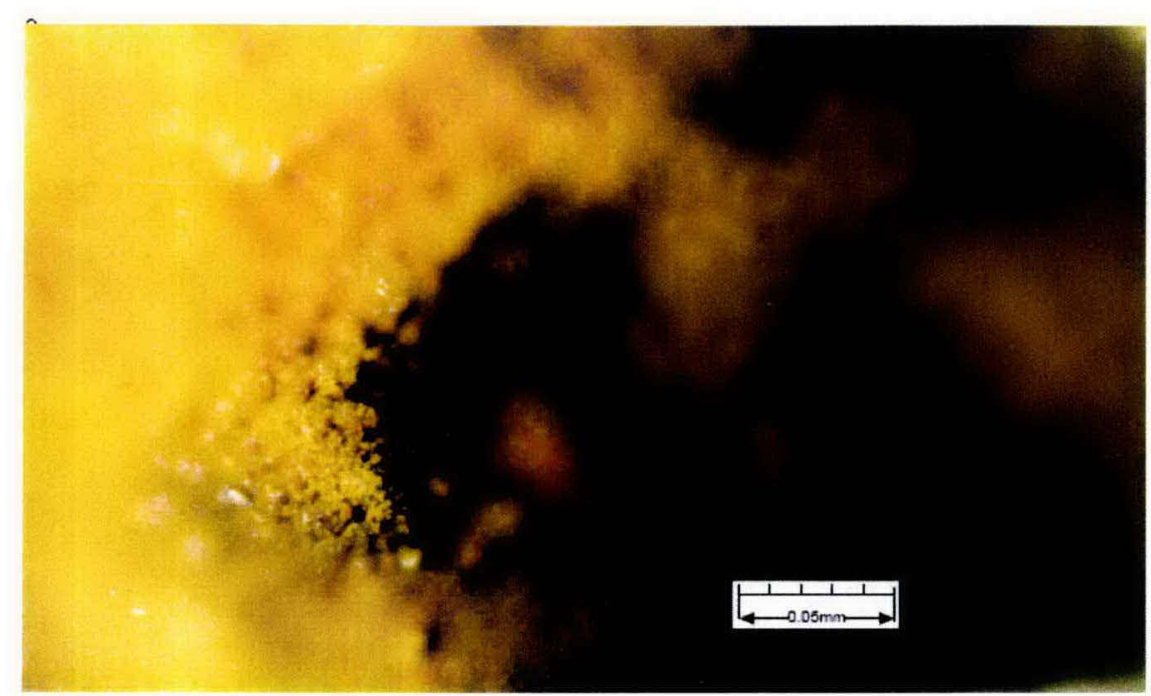

Figure 2: Surface Deposits Around Pit

As noted above, the $219 \mathrm{~S}$ tanks contain chloride concentrations of over $1000 \mathrm{ppm}$. Based on data from CSI Alloys, Figure 3, care must be taken in controlling the $\mathrm{pH}$ - the lower line, $0 \% \mathrm{Mo}$ is the curve for $304 \mathrm{~L}$ and 347 stainless. Chloride concentrations below the line at a given $\mathrm{pH}$ are acceptable.

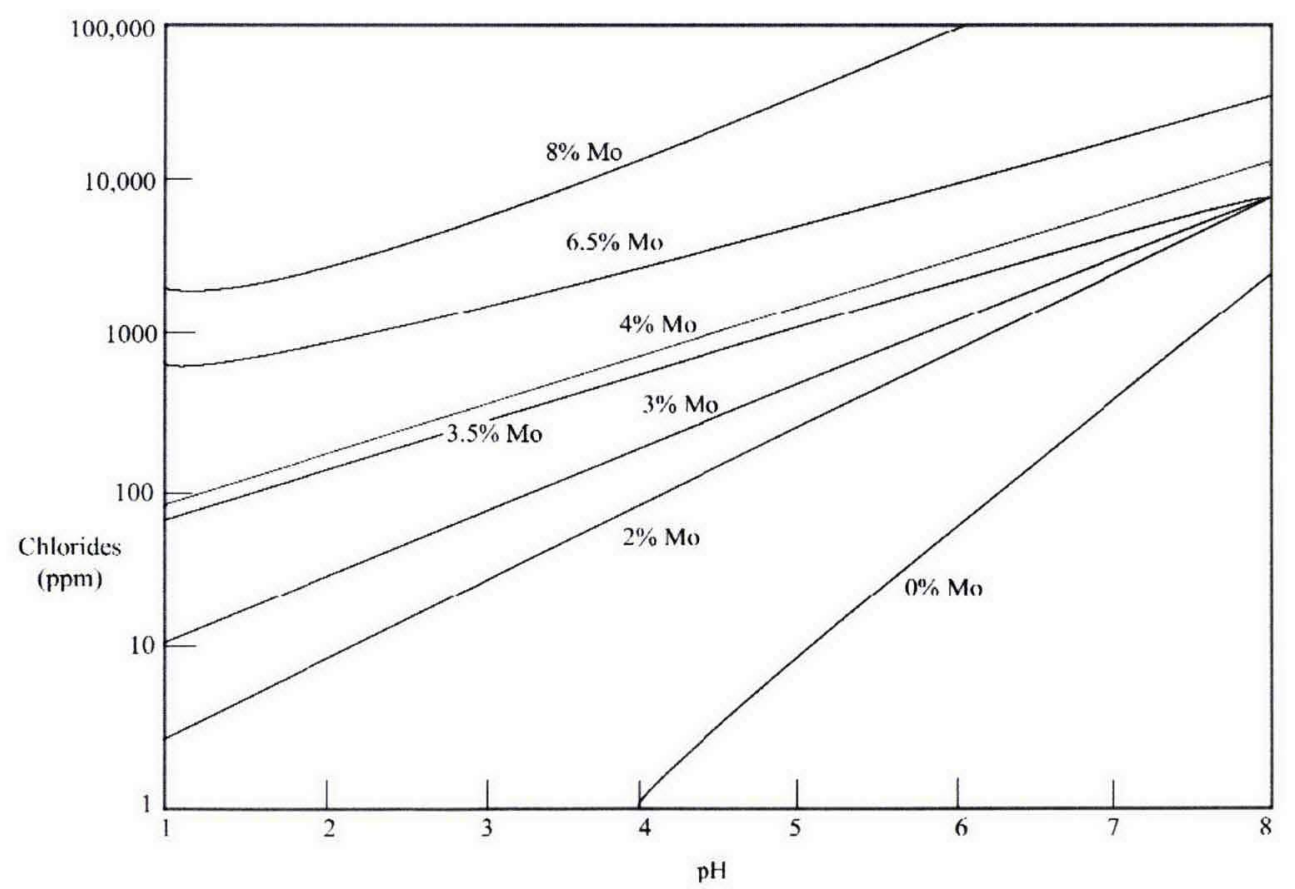

Figure 3: Chloride vs. pH limits for Stainless Alloys

Thus it is clear that for $1000 \mathrm{ppm}$ chloride, a $\mathrm{pH}>8$ is required. In fact with the uncertainties of chloride concentration and the higher values found in the drains, it would be advised to operate at $\mathrm{pH} 12$ or higher at all times. There are reports that at $\mathrm{pH} \gg>12$, pitting is unlikely. 


\subsection{Conclusions}

Because of the high chloride concentrations in the $222 \mathrm{~S}$ Laboratory wastes, it is strongly advised that the Laboratory Operating Procedures be revised to ensure that the $\mathrm{pH}$ in the drain lines is maintained above $\mathrm{pH}$ 12. This does not mean it has to be that value constantly, but the less the time below pH 12, the better. Hence at the conclusion of a day's operation, it is advisable to treat the lines with a caustic rinse. Further, the tanks should always be maintained above $\mathrm{pH} 12$ to minimize the opportunity for failure.

There is one caveat to remember. Pitting does not occur instantly and there is no effective means to stop a pit once started. Hence, future leaks should be anticipated but at a declining rate, unlike what is expected if no change of procedure occurs, see Figure 4.

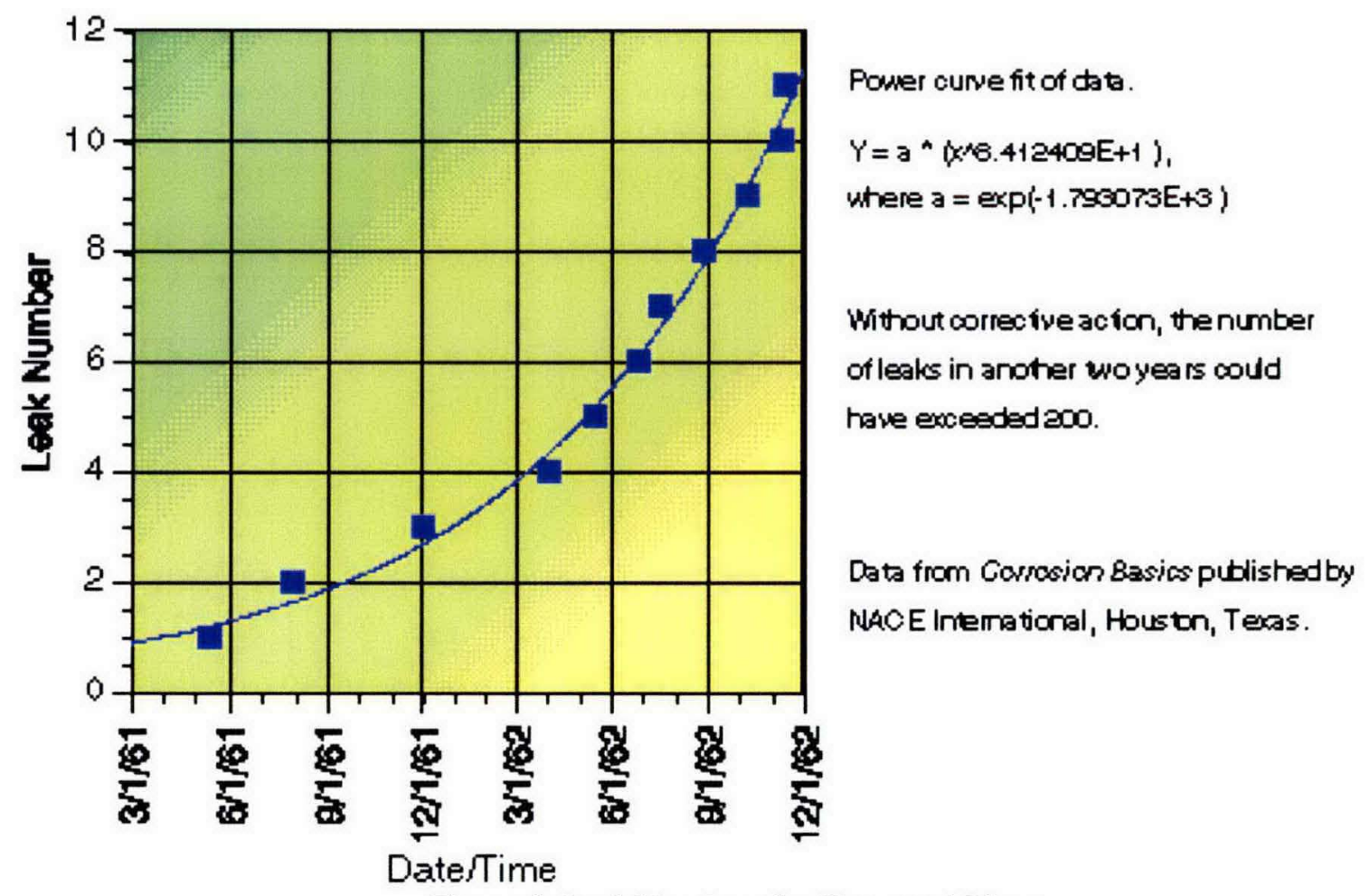

Figure 4: Leak Numbers for Untreated Lines

\subsection{Recommendations}

Modify the Operating Procedures in accordance with the recommendations made at the final committee meeting. Those recommendations are as follows:

1. Acidic material is disposed of with generous water flush,

2. "Neutral" $(2 \leq \mathrm{pH} \leq 12)$ is flushed next,

3. Basic material $\mathrm{pH} \geq 12$ is disposed of last,

4. Followed by 1 to 2 drain line volumes of at least a 0.5 molar $\mathrm{NaOH}$ flush. 
RPP-39617, Rev. 0

219S-CML-8

PAGE 8 of 8

Distribution

$\begin{array}{ll}\text { G Parsons } & \text { T6-04 } \\ \text { D Comstock } & \text { T6-04 } \\ \text { H Baune } & \text { T6-04 } \\ \text { L Borneman } & T 6-03 \\ \text { K Hall } & T 6-02 \\ \text { J Frye } & T 6-07 \\ \text { J Duncan } & T 6-50 \\ \text { C Seidel } & T 6-14 \\ \text { D Renberger } & T 6-03 \\ \text { D Hardy } & T 6-14 \\ \text { R Schroeder } & \text { T6-10 }\end{array}$

